\title{
Quantitative Assessment of Orbital Volume and Intraocular Pressure after Two-Wall Decompression in Thyroid Ophthalmopathy
}

\author{
Sang Min Park ${ }^{1}$, \\ Su Bong Nam, \\ Jae Woo Lee ${ }^{1}$, \\ Kyeong Ho Song ${ }^{1}$, \\ Soo Jong $\mathrm{Choi}^{1}$, \\ Yong Chan Bae ${ }^{1,2}$ \\ ${ }^{1}$ Department of Plastic and Reconstructive \\ Surgery, Pusan National University School \\ of Medicine, Busan; ${ }^{2}$ Biomedical Research \\ Institute, Pusan National University Hospital, \\ Busan, Korea
}

No potential conflict of interest relevant to this article was reported.

\begin{abstract}
Background: Surgical outcomes after orbital wall decompression have focused on the degree of exophthalmos and intraocular pressure. The aim of this research was to evaluate intraorbital volume using computed tomography (CT) images following two-wall decompression using a combined subcilliary and endoscopic approaches. Methods: A retrospective review was performed for all patients who had undergone the two-wall decompression method. The pre/postoperative CT images were used to evaluate changes in intraocular volume. Intraocular pressure was evaluated using applanation tonometry. Surgical details are discussed within the body of text.

Results: Two-wall decompression thru the medial wall and floor was associated with an average intraorbital volume change of $7.3 \mathrm{~cm}^{3}$, with maximal accommodation up to $13 \mathrm{~cm}^{3}$. Changes in intraocular pressures were not statistically significant.

Conclusion: Two-wall decompression was effective in accommodation of up to 13 $\mathrm{cm}^{3}$ of soft tissue herniation. There was no statistically significant association between changes in volume to pressure.
\end{abstract}

Keywords: Hyperthyroidism / Orbital disease / Intraocular pressure / Decompression, surgical

\section{INTRODUCTION}

Thyroid disease, intraorbital tumor, and arteriovenous aneurysms are associated with proptosis and increased intraocular pressure, with hyperthyroidism (Graves disease) being the most common. Since introduction of single-wall decompression (medial wall) by Kronlein-Berke, a variety of methods have been introduced [1,2]. The main purpose of orbital decompression is to minimize the functional complications arising from intraorbital hypertention and to address the aesthetic issue of bulging eyes. However, clinical outcomes have been analyzed using exophthalmometry and/

Correspondence: Su Bong Nam

Department of Plastic and Reconstructive Surgery, School of Medicine, Pusan National University, 20 Geumo-ro, Mulgeum-eup, Yangsan 50612, Korea E-mail: subong71@hanmail.net

*This work was supported by a clinical research grant from Pusan National University Yangsan Hospital 2014

Received February 15, 2015 / Revised March 26, 2015 / Accepted August 4, 2015 or other forms of ophthalmological examination, with few studies reporting quantitative changes in intraocular pressure. In this study, we report changes in intraorbital volume using computed tomography (CT) images and in intraocular pressure (IOP) from before to after two-wall decompression in patients with thyroid ophthalmopathy.

\section{METHODS}

\section{Subjects and period}

A single-institutional retrospective review was performed for thyrotoxic ophthalmopathy patients requiring decompression of the orbit. The review identified 7 patients, all of whom underwent two-wall decompression (unilateral orbit in 5 patients and bilateral orbit in 2 patients). The mean age was 54.1 years (range, 41-68 
years), with 4 male and 3 female patients. All of the patients had received appropriate hyperthyroidism treatment (medications and/ or thyroidectomy). The average time from hyperthoyroid diagnosis-to-proptosis was 12 months, ranging from 3 to 20 months.

Orbital volume was evaluated before and after the operation using orbital CT images. IOP was measured at same period after the operation when they visited the department of ophthalmology as outpatients using an applanation tonometer (Haag-Streit International, Koeniz, Swiss).

\section{Surgical methods}

\section{Subciliary access}

Under general anesthesia, the subciliary incision was designed. Lidocaine/epinephrine mixture was injected along the eyelashes. The incision was carried through the dermis, and the dissection was carried inferiorly in the plane above the orbicularis muscle. At the inferior border of tarsal plate, the access was continued deep to the orbicularis muscle, anterior to the septum. The periosteum was opened 2-mm below the orbital rim, and the subperiosteal space was dissected widely to expose the orbital floor, while avoiding injury to the lacrimal sac, medial canthal tendon, inferior oblique muscle, and the inferior orbital neurovascular bundle.

\section{Transnasal endoscopic access}

The medial wall was approached using a transnasal approach. After exposing the orbital floor through the subciliary access, the ipsilateral nasal cavity was prepared with cottonoid soaked with diluted epinephrine. Additionally, the lidocaine/epinephrine mixture was injected widely into submucosa. The uncinate process was removed to expose the maxillary meatus, which was widened for access to the underside of orbial floor. The medial orbital wall was exposed by pushing the middle turbinate medially with the mucosa dissected in anterior-to-posteorior direction.

\section{Methods and range of decompression}

With adequate exposure of medial wall and orbital floor, a periosteal elevator was used to fracture the walls. The fracture fragments were removed using fine tipped endoscopic rongeur and forceps. Thicker portion of the walls were resected using osteotome and burr. The medial wall was decompressed from the posterior ethmoidal sinus to the anterior sphenoid body, to the neighboring cribriform plate, and to the posterior wall of the nasolacrimal duct. The orbital floor was removed with a 5-mm margin left intact along the orbital rim. All of the bone medial to the infraorbital groove was removed, which was continued into the medial wall under endoscopic vision.

After completion of the bone removal, the periorbital tissue was incised for soft-tissue decompression as needed. Three or four incisions were made in the anteroposterior direction, while evaluating the degree of orbital fat herniation with manual reduction of the globe. If proptosis was severe enough, the periorbita was opened completely to allow further herniation of the orbital soft tissue into the ethmoid and maxillary sinus.

Any bleeding from exposed bone was controlled using Surgicel (Ethicon, Somerville, NJ, USA). The empty spaces were filled with Merocel(Medtronic, Minneapolis, MN, USA), and the ipsilateral nare was blocked with cotton upon withdrawal of endoscope. The subcilliary access was closed in layers. To minimize the risk of ectropion, atraction suture was placed in the lower eyelid margin and taped towards the eyebrow.

At each of the operation, an opthlamologist was present to evaluate for optic and oculomotor functions (pupillary reflex and forced duction tests), all of which were normal at the time of dressing.

\section{Postoperative treatment}

Nasal packing, merocel, and traction sutures were removed after 3 to 5 days. Patients were discharged home after 7 days and followed at week 2 and at months 1,2, 4, and 6 .

\section{Measurement of orbital volume}

Orbital volumes were evaluated using available axial CT study data (Fig. 1). The boundary was traced along the bony boundary, and the axial area containing the soft-tissue was calculated using the 'measure area' function. The sum of axial area was multiplied by the CT image thickness to obtain the intraorbital volume. The 
orbital volumes were compared between preoperative and postoperative imaging for each patient.

\section{Intraocular pressure measurement}

IOP was assessed using applanation tonometer before and after the operation by ophthalmologists.

\section{Statistical analysis}

Changes in orbital volume and IOP measurements were analyzed using Wilcoxon signed-ranks test.

\section{RESULTS}

The mean preoperative orbital volume was $22.9 \mathrm{~cm}^{3}$, and the mean postoperative volume was $30.2 \mathrm{~cm}^{3}$. The mean difference between pre and postoperative measurements was $7.3 \mathrm{~cm}$, with a

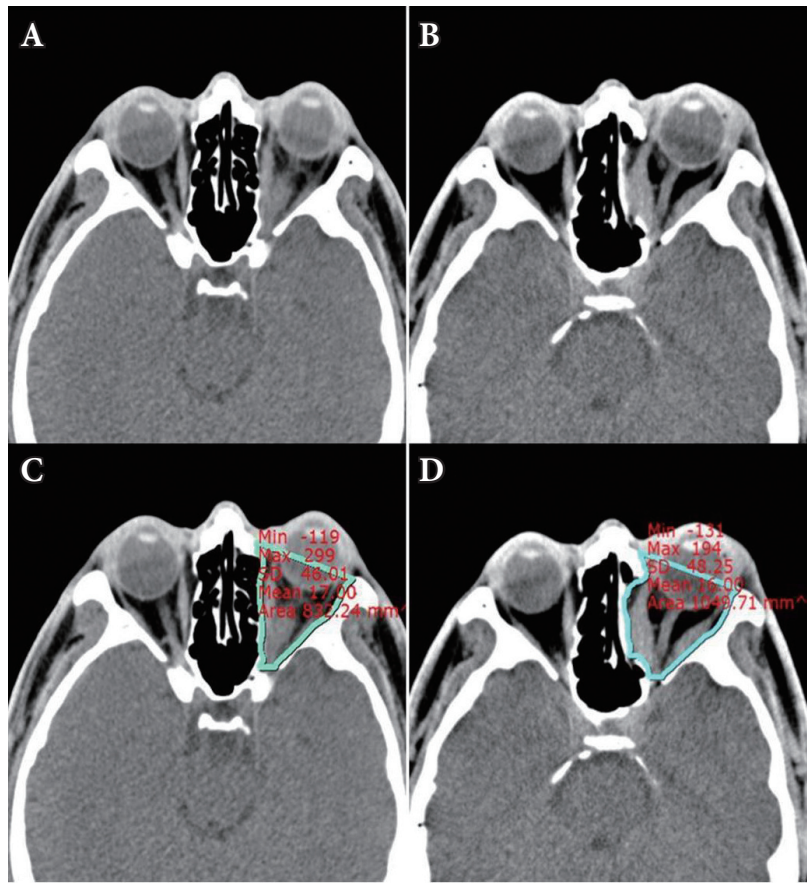

Fig. 1. Preoperative and postoperative computed tomography (CT) images. (A, C) Preoperative CT image and measurement of orbital volume by picture archiving communication system (PACS), (B, D) Postoperative CT image and measurement of orbital volume by PACS. range between 3 and $13 \mathrm{~cm}^{3}$ (Table 1). The mean pre and postoperative IOP was 20.2 and $18.1 \mathrm{~mm} \mathrm{Hg}$, respectively. The difference in IOP ranged from -13 to $-3 \mathrm{~mm} \mathrm{Hg}$, with a mean decrease of 2.1 mm Hg (Table 2).

Out of the 9 orbital decompressions, orbital volume had increased significantly from preoperative to postoperative evaluation $(p=0.005)$. The difference in intraocular measurements was not statistically significant $(p=0.240)$ with variable distribution of IOP change across the operated eyes (Table 3).

\section{DISCUSSION}

In patients with thyrotoxic ophthalmopathy, the purpose of orbital decompression is to allow the increased volume of orbital soft

Table 1. Preoperative and postoperative orbital volume change

\begin{tabular}{|llccc} 
Case & Site & $\begin{array}{c}\text { Preoperative } \\
\text { orbital volume } \\
\left(\mathrm{cm}^{3}\right)\end{array}$ & $\begin{array}{c}\text { Postoperative } \\
\text { orbital volume } \\
\left(\mathrm{cm}^{3}\right)\end{array}$ & $\begin{array}{c}\text { Change of } \\
\text { volume } \\
\left(\mathrm{cm}^{3}\right)\end{array}$ \\
\hline 1 & Left & 23 & 30 & +7 \\
\hline 2 & Right & 27 & 31 & +4 \\
\hline 3 & Left & 15 & 24 & +9 \\
\hline 4 & Right & 16 & 24 & +8 \\
\hline 5 & Left & 30 & 41 & +11 \\
\hline 6 & Right & 30 & 43 & +13 \\
\hline 7 & Left & 21 & 29 & +8 \\
\hline Average & Left & 20 & 23 & +3 \\
\hline
\end{tabular}

Table 2. Preoperative and postoperative intraocular pressure (IOP) changes

\begin{tabular}{|llccc|} 
Case & Site & $\begin{array}{c}\text { Preoperative } \\
\text { IOP }(\mathrm{mm} \mathrm{Hg})\end{array}$ & $\begin{array}{c}\text { Postoperative } \\
\text { IOP }(\mathrm{mm} \mathrm{Hg})\end{array}$ & $\begin{array}{c}\text { Change of } \\
\text { IOP }(\mathrm{mm} \mathrm{Hg})\end{array}$ \\
\hline 1 & Left & 24 & 22 & -2 \\
\hline 2 & Right & 24 & 16 & -8 \\
\hline 3 & Right & 12 & 12 & 0 \\
\hline & Left & 13 & 12 & -1 \\
\hline 4 & Right & 16 & 18 & +2 \\
\hline 5 & Left & 15 & 18 & +3 \\
\hline 6 & Left & 22 & 21 & -1 \\
\hline 7 & Left & 16 & 17 & +1 \\
\hline Average & Right & 40 & 27 & -13 \\
\hline & & 20.2 & 18.1 & -2.1 \\
\hline
\end{tabular}


Table 3. Postoperative changes of orbital volume and intraocular pressure (IOP)

\begin{tabular}{llcc} 
Case & Site & Change of volume $\left(\mathrm{m}^{3}\right)$ & Change of IOP $(\mathrm{mm} \mathrm{Hg})$ \\
\hline 1 & Left & +7 & -2 \\
2 & Right & +4 & -8 \\
\hline 3 & Right & +9 & 0 \\
& Left & +8 & -1 \\
\hline 4 & Right & +11 & +2 \\
\hline 5 & Left & +13 & +3 \\
\hline 6 & Left & +8 & -1 \\
\hline 7 & Left & +3 & +1 \\
Average & Right & +3 & -13 \\
\hline
\end{tabular}

tissue to herniate into ethmoidal and maxillary sinus. Various methods of decompression have been introduced, depending on anatomic and operative considerations as well as operator preference. The ideal technique must permit adequate decompression of the orbital content, while maintaining optic and extraocular motor functions with minimal risk of complications. Krönlein introduced the approach into the orbit in 1888, and orbital decompression was first reported by Dollinger. Subsequent to this, lateral wall orbital decompression was standardized by Berke. Orbital floor decompression was introduced by Hirsch, and Walsh and Ogura et al. had combined the medial wall and orbital floor decompression for a two-wall decompression. In addition, various surgical techniques including three wall orbital decompression by Tessier and Wolfe, and four wall orbital decompression by Maroon-Kennerdell have been introduced [1,2].

Two-wall decompression has been reported to result in good outcomes without serious complications. Among single-wall techniques, the space beyond medial wall is known to accommodate the most volume of soft tissue herniation. In addition, medial wall decompression was associated with a more effective protection for compressed optic nerve, as it is located medially in the posterior orbital wall [3-5]. Single-wall decompressions; however, can often result in an off-axis mobilization of the eye with resulting diplopia. This is most likely due to the fact that thyrotoxic ophthalmopathy tends to involve hypertrophy of the medial and inferior rectus muscles [6-8].

Concomittant decompression through the medial and lateral walls is effective. If correction of proptosis is the main purpose, it is more effective to decompress the lateral orbital wall. However, it may reduce postoperative diplopia, which is still controversial. In lateral wall decompression, the entire superolateral area of the orbit is necessary to expose the anterior cranial fossa and dura mater of middle cranial fossa, which is associated with serious intracranial complications andincreased operative time. In addition, herniation thru the lateral wall allows conduction of masticatory forces from temporalis muscle to the orbit, which results in the eyeball moving with chewing [9].

Few studies have evaluated orbital volume in a quantitative manner following decompression [6]. Most studies have evaluated postsurgical outcomes in terms of proptosis (Hertel exophthalmometry) and/or intraocular pressure (tonometer). In the present study, we have adopted a method of orbital volume assessment previously developed for evaluation of orbital fracture [10,11].

Among the 9 orbits in our review, two-wall decompression was associated with an average of $7.3 \mathrm{~cm}^{3}$ increase in intraorbital volume. In a study published in 2014, Kim et al. [6] had reported changes in orbital volume after single-wall decompressions. Single-wall decompression was associated with average increase of $0.51 \mathrm{~cm}^{3}$ for medial wall-only and $0.11 \mathrm{~cm}^{3}$ for floor-only decompressions. In 1983, Stabile and Trokel [12] had simulated orbital volume changes using cadaveric cranium models and reported that the orbital medial wall could accommodate for $6 \mathrm{~mL}$ of soft tissue volume and that the orbital floor further permit $7 \mathrm{~mL}$ of herniation. The authors also reported that simultaneous herniation thru both walls could allow as much as $15 \mathrm{~mL}$ of orbital volume to herniate. Our results are in agreement with the theoretical upper limits of soft tissue herniation that is made possible by concomitant decompression with maximal increase of $13 \mathrm{~cm}^{3}[6,12]$.

Two-wall decompression in our study was associated with a 2.1 $\mathrm{mmHg}$ decrease in IOP, but this result was not statistically significant. In patients with normal preoperative IOP (11-20 mm Hg), the postoperative IOP was not different, and most of the large reduction in IOP could be attributed to those patients with intraocular hypertension. Though the orbital volume was increased, some of the patients continued to demonstrate intraocular hypertension. In 2008, Sagili et al. [13] reported that orbital decompres- 
sion was not associated with significant reductions in IOP.

Diplopia after orbital decompression may be related to off-axis mobilization of the eyeball $[13,14]$. Orbital wall decompression is associated with newly developed postoperative diplopia in approximately $30 \%$ of the operation, which is probably the most significant concern for this operation [15]. For correction of diplopia after orbital decompression, a strabismus operation can be performed if the diplopia did not improve after 12 months. To reduce the occurrence of lower strabismus or medial strabismus, balanced orbital decompression which removes the medial and lateral orbital walls at the same time may be considered. Because such a surgical method requires mastery of a wide range of surgical techniques and has potential risks and complications, it may be controversial to attempt this method preferentially [9].

Two-wall decompression thru the medial wall and floor was associated with an average intraorbital volume change of $7.3 \mathrm{~cm}^{3}$, with maximal accommodation up to $13 \mathrm{~cm}^{3}$. Change in IOP was not statistically significant.

\section{REFERENCES}

1. McCarthy JG. Plastic surgery. Philadelphia: Saunders; 1990.

2. Mathes SJ, Hentz VR. Plastic surgery. Philadelphia: Saunders Elsevier; 2006.

3. Goh MS, McNab AA. Orbital decompression in Graves' orbitopathy: efficacy and safety. Intern Med J 2005;35:586-91.

4. Chang EL, Bernardino CR, Rubin PA. Transcaruncular orbital decompression for management of compressive optic neuropathy in thyroid-related orbitopathy. Plast Reconstr Surg 2003;112:739-47.
5. McCann JD, Goldberg RA, Anderson RL, Burroughs JR, Ben Simon GJ. Medial wall decompression for optic neuropathy but lateral wall decompression with fat removal for non vision-threatening indications. Am J Ophthalmol 2006;141:916-7.

6. Kim KW, Byun JS, Lee JK. Surgical effects of various orbital decompression methods in thyroid-associated orbitopathy: computed tomography-based comparative analysis. J Craniomaxillofac Surg 2014; 42:1286-91.

7. McCord CD Jr, Putnam JR, Ugland DN. Pressure-volume orbital measurement comparing decompression approaches. Ophthal Plast Reconstr Surg 1985;1:55-63.

8. Krastinova-Lolov D, Bach CA, Hartl DM, Coquille F, Jasinski M, Cecchi P, et al. Surgical strategy in the treatment of globe protrusion depending on its mechanism (Graves' disease, nonsyndromic exorbitism, or high myopia). Plast Reconstr Surg 2006;117:553-64.

9. Sellari-Franceschini S, Lenzi R, Santoro A, Muscatello L, Rocchi R, Altea MA, et al. Lateral wall orbital decompression in Graves' orbitopathy. Int J Oral Maxillofac Surg 2010; 39:16-20.

10. Choi SJ, Oh HC, Nam SB, Kang CU, Bae YC. The reconstruction of the extensive inferior blow-out fracture through endoscopic transnasal and subciliary approaches. J Korean Cleft Palate-Craniofac Assoc 2009;10:86-90.

11. Lee JW, Nam SB, Choi SJ, Kang CU, Bae YC. Perioperative orbital volume change in blowout fracture correction through endoscopic transnasal approach. J Korean Soc Plast Reconstr Surg 2009;36:617-22.

12. Stabile JR, Trokel SM. Increase in orbital volume obtained by decompression in dried skulls. Am J Ophthalmol 1983;95:327-31.

13. Sagili S, Desousa JL, Malhotra R. Intraocular pressure and refractive changes following orbital decompression with intraconal fat excision. Open Ophthalmol J 2008;2:73-6.

14. Norris JH, Ross JJ, Kazim M, Selva D, Malhotra R. The effect of orbital decompression surgery on refraction and intraocular pressure in patients with thyroid orbitopathy. Eye (Lond) 2012;26:535-43.

15. Mainville NP, Jordan DR. Effect of orbital decompression on diplopia in thyroid-related orbitopathy. Ophthal Plast ReconstrSurg 2014;30:137-40. 